\title{
COVID-19 Era and Water Supply: Challenges for Rural Communities in Eastern, Nigeria
}

\author{
Tonia Nkiru Nwobodo ${ }^{*}$, Kevin Ejike Chukwu ${ }^{2}$ \\ ${ }^{1}$ Department of Geography, University of Nigeria, Nsukka, Nigeria \\ ${ }^{2}$ Department of Geography and Meteorology, Enugu State University of Science and Technology, Enugu, Nigeria \\ Email: ^toniaonline007@yahoo.com, chukwu.kevin@esut.edu.ng
}

How to cite this paper: Nwobodo, T. N., \& Chukwu, K. E. (2020). COVID-19 Era and Water Supply: Challenges for Rural Communities in Eastern, Nigeria. Journal of Geoscience and Environment Protection, 8, 219233.

https://doi.org/10.4236/gep.2020.87013

Received: June 12, 2020

Accepted: July 28, 2020

Published: July 31, 2020

Copyright $\odot 2020$ by author(s) and Scientific Research Publishing Inc. This work is licensed under the Creative Commons Attribution International License (CC BY 4.0).

http://creativecommons.org/licenses/by/4.0/

\begin{abstract}
Coronavirus is currently a huge threat to human health all over the globe. Even though it has no cure yet, it can be contained by proper personal and collective hygiene. This makes access to sufficient clean water supply fundamental and indispensable. Since rural communities tend to be vulnerable to disease outbreaks due to poor standards of hygiene, this study examined the challenges of the rural communities in Enugu West Senatorial District in Nigeria over access to clean water supply and their preparedness to tackle COVID-19 pandemic, following the guidelines from world health experts. The survey showed general awareness of the pandemic in the selected communities. However, $71 \%$ neither have access to clean water supply, nor alternative to hand sanitizing agent. A large number of the respondents also acknowledged that availability and accessibility to clean water supply would improve the hygiene culture of the people and as a result curtail the spread of the disease. This study, therefore, recommends that government should intervene by extending water borehole projects and water treatment plants to various rural communities as well as providing maintenance services for non-functional ones.
\end{abstract}

\section{Keywords}

Accessibility, Availability, Challenges, COVID-19, Nigeria, Water Supply

\section{Introduction}

Novel Coronavirus also referred to as COVID-19 is a pandemic disease. The global update as of $7^{\text {th }}$ April, 2020 records, 1,419,256 of the disease cases, 81,526 death toll and 301,497 recovered cases (Worldometer, 2020). Nigeria particularly records 254 of the disease cases, 6 death toll and 44 recovered cases as of $7^{\text {th }}$ April, 2020 (NCDC, 2020). The extent of its transmission depends on people's 
hygienic lifestyle. Proper hygiene can be achieved through cleanliness (Kumwenda, 2019), which water is a basic input for that outcome. Water being a fundamental human right has put the locus of Sustainable Development Goals (SDG6.1) on making it able to be reached on premises, available and safe by 2030 (Hutton, 2016; Shaheed et al., 2014).

This is a global task not only for developing and under-developed countries (Omarova et al., 2018). The commitment to "leave no one behind" needs total attention on rural communities, which are often forgotten majorly by poor governance (WWAP, 2019). About 844 million people globally lack access to basic water supply which $79 \%$ out of them are rural dwellers (WHO, 2017). Even so, 2.1 billion people lack safely managed drinking water supply system service. This denotes that $14.9 \%$ of the urban and $45.2 \%$ of the rural inhabitants need enhanced services (WHO and UNICEF, 2017).

Lack of adequate water supply is one of the most serious challenges of the twenty-first century (Elimelech, 2006). Particularly, rural communities are majorly affected (Tadesse et al., 2013). One-third of the world's population lives in water-stressed countries and, by 2025 , this figure is expected to rise to two-thirds (Elimelech, 2006) except proactive measures are adopted. Inadequate water supply is majorly caused by lack of political will, poor facility maintenance, spatial inequality in service delivery, sabotage of implementation of various policies related to the delivery of water services (Abubakar, 2016).

Ruling out inequalities within and among countries (SDG 10) is the central concern in Sustainable Development Goals (SDGs) era as well as ensuring availability and sustainability management of water and sanitation for all (Ezbakhe et al., 2019). Total involvement of the government and communities' participation will be necessary towards achieving this goal. Unsatisfactory provision of basic amenities such as water for adequate hygiene and sanitation can have deleterious effect on living conditions of people (Behera et al., 2020). Poor access to clean water can affect health and well being. This brought about the commitment of Sustainable Development Goal 3 in ensuring a healthy life and promoting well being for all (Guégan et al., 2018). To maintain personal hygiene, a person needs 50 to 100 litres of water per day (Rumalongo et al., 2017). This will leave people with a limit of 20 litres of water per day vulnerable to a high level of health challenges (Omarova et al., 2018). Poor economic background of the rural communities also affects the volume of water they use (Bain et al., 2014) and this significantly influences their hygiene lifestyle.

The outbreak of COVID-19 and its potential environmental transmission indicates the need for proactive measures. This will help flatten the curve to avoid subsequent occurrence unlike the Spanish flu that spread around the world in three consecutive waves (Short et al., 2018), because it was not properly contained. Control interventions of any form of disease largely depend on hygiene. Availability of clean water supply to maintain proper hygiene especially by constant washing of hands is one of the key preventive measures for the novel coronavirus (COVID-19). Based on world health experts, hands should be washed 
regularly using soap and running water for 20 - 40 seconds (WHO, 2020). Rural communities in Nigeria have been marginalized in terms of access to clean water supply. These poor dwellers may not have the luxury of affording hand sanitizers, which is another alternative for hand hygiene in the absence of water. This put them at high risk towards contracting and spreading the disease.

Transmission of COVID-19 can be contained by the following proactive measures; nose masks wearing, hand hygiene practices, avoidance of public places, case detection, contact tracing, physical distancing and quarantines (Adhikari et al., 2020). This is because; there is no established antiviral treatment yet. It can be transmitted from person-to-person when an individual with the infection emits droplets containing virus particles while talking, sneezing and coughing. The droplets could drop on the nose or eye of another person, usually within a distance of $6 \mathrm{ft}(1.8 \mathrm{~m})$ but perhaps farther (Bourouiba, 2020). They can also drop on stationary or movable objects which can be transferred to another person when they come in contact with these fomites. However, proper hygiene is necessary in reducing contamination of surfaces (Kampf et al., 2020).

In Nigeria, general access to water supply and sanitation facilities by citizens has remained very poor (Akpabio, 2012). Most rural communities lack access to adequate water supply till date. The residents resort to various sources for their basic water use based on availability, accessibility and affordability. This to a degree would influence maintaining proper hygiene which can speed up spread of diseases. The rural communities in eastern Nigeria majorly rely on river water as their primary source of water for domestic use. Few communities have borehole water supply projects. Few others dug well in their premises which sometimes dry up during the dry season. Family members travel long distance in some occasions to fetch water for domestic use. All these invariably affect the volume of water they use especially for personal hygiene.

Recent studies on the current pandemic, majorly explored the epidemiology, causes, clinical manifestation and diagnosis, as well as prevention and control of the novel coronavirus. However, little or no attention has been given to challenges of water supply in the rural communities to promote and maintain the regular hand washing protocols as directed by world health experts hence, the need for this study. This study aims at assessing the challenges of rural communities in Enugu West Senatorial district to the COVID-19 in terms of access to clean water supply for proper hygiene. It employed simply frequencies and percentages in analyzing the data. The result showed that the rural communities are at high risk of contracting and spreading COVID-19 disease due to lack of access to adequate water supply. It recommends government swift intervention by extending water borehole projects and water treatment plants to various rural communities as well as providing maintenance services for non-functional ones.

\section{Materials and Method}

\subsection{Study Area}

The study area is Enugu West Senatorial District. It lies between latitude 
$5^{\circ} 53^{\prime} 40^{\prime \prime}$ and $6^{\circ} 40^{\prime} 55^{\prime \prime}$ North and longitude $6^{\circ} 59^{\prime} 50^{\prime \prime}$ and $7^{\circ} 44^{\prime} 5^{\prime \prime}$ East as shown in Figure 1. The population of the area as of 2006 population was 871,162 (NPC, 2006) and the projected population is $1,218,320$ (2019 projected). The population rate is $2.83 \%$ (Nzeadibe \& Ajaero, 2010). The study area comprises five local government areas, Aninri, Awgu, Oji-River, Ezeagu and Udi. In all the sampled communities, access to water supply has been a huge challenge except Obinaofia Ndiagu in Ezeagu local government area that has constant water supply in their various premises. This is due to the World Bank assisted water project in that community. The project was done to remediate flooding disaster in that area.

\subsection{Research Design}

The research design used was survey design. Cochran formula was used to determine the sampling size of respondents and 384 samples were obtained. 384

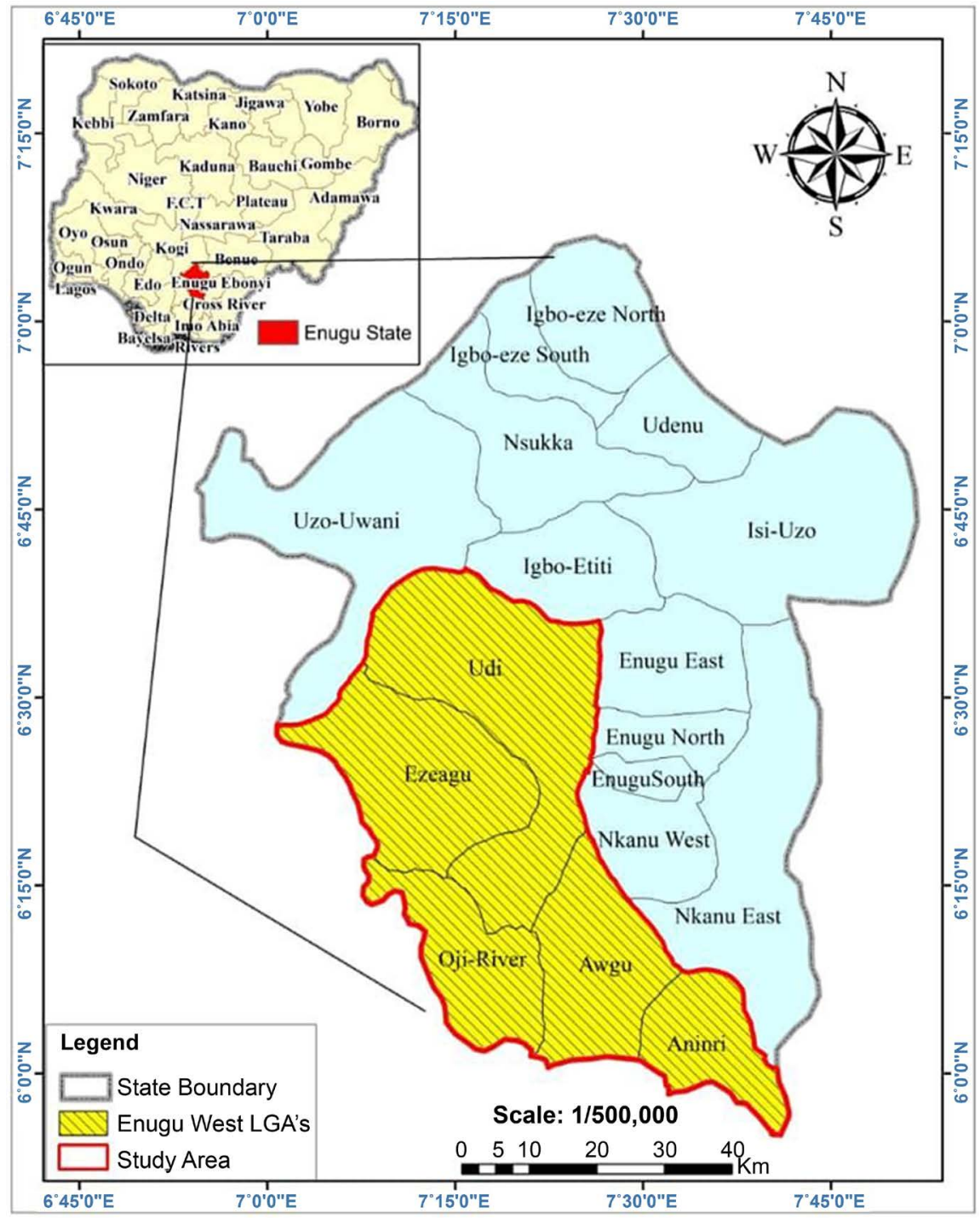

Figure 1. Map of the study area. Source: Google map, 2020. 
copies of the sample questionnaire were administered to households in the study area. The questionnaire was grouped into three namely, socio-demographic characteristics of the respondents, water usage and sources in the sample communities and COVID-19 awareness and preparedness in the sampled communities. The sampling technique employed was proportionate and random sampling. The five local government areas were represented with alphabets; A denotes Aninri, B denotes Awgu, C denotes Oji-River, D denotes Ezeagu and E denotes Udi. Three different communities were selected by balloting to represent each local government area. A pilot study was carried out in Oduma community covering 20 households in Aninri LGA, this was done to test the validity and reliability of the instrument (questionnaire). In each of the community every $5^{\text {th }}$ household was selected. The questionnaire was administered one person per household, to avoid duplication. Simple frequencies and percentages generated from the analysis were presented in tables and figures to discuss data and information on the issues addressed by the study objectives.

\section{Results and Discussion}

\subsection{Socio-Demographic Characteristics}

Table 1 shows the socio-demographic characteristic of the respondents. The percentage distribution of the total audience comprises 51\% females and $49 \%$ males. This showed that the female population is dominant in the distribution compared to the males. From the result analysis, 31\% are single, 56\% are married and $13 \%$ are others which comprises, divorced, separated, widows and widower. The distribution of their ages showed $12 \%$ for age $20-30 \mathrm{yrs}, 24 \%$ for 31 - 40 years, $43 \%$ for 41 - 50 years, $15 \%$ for 51 - 60 years and $6 \%$ for 61 years and above. The education level of the respondents varies, $14 \%$ have degree qualification, $74 \%$ have secondary education and $12 \%$ have primary education. The result revealed that secondary school education gain dominance in the study area with $74 \%$. Literacy level will have significant effect on quality and quantity of water used by household in relation to hygiene. The survey showed that $13 \%$ are civil servants, $14 \%$ are traders, $71 \%$ are farmer while $2 \%$ are into craft. This revealed that the major occupation of people in the study area is farming. Owing to the fact of longer time spent on farm will affect the time available for fetching water. This will affect the quantity of water available for domestic consumption, which may invariably affect proper hygiene maintenance. The income distribution showed that 3\% earns above N30,000 monthly, 7\% earns between N25,000 $\mathrm{N} 30,000,23 \%$ earns between N20,000 - N25,000, 59\% earns between N15,000 $\mathrm{N} 20,000$ and $8 \%$ earns between N10,000 - N15,000. This showed that the people in the study area are very low income earners. This may have great influence on affordability of water supply and willingness to contribute to the maintenance of existing borehole in some communities. The household size distribution showed that $3 \%$ have $1-2$ family members, $33 \%$ have 4 - 6 family members, $59 \%$ have 7 - 8 family members $5 \%$ have 8 - 10 family members. The result showed that $59 \%$ 
Table 1. Socio-demographic characteristics of the respondents.

\begin{tabular}{|c|c|c|c|c|c|c|c|c|c|c|c|}
\hline & \multicolumn{2}{|c|}{$\begin{array}{c}\text { A } \\
\text { Freq. \% }\end{array}$} & \multicolumn{2}{|c|}{$\begin{array}{c}\text { B } \\
\text { Freq. \% }\end{array}$} & \multicolumn{2}{|c|}{$\begin{array}{c}\text { C } \\
\text { Freq. \% }\end{array}$} & \multicolumn{2}{|c|}{$\begin{array}{c}\text { D } \\
\text { Freq. \% }\end{array}$} & \multicolumn{2}{|c|}{$\begin{array}{c}\text { E } \\
\text { Freq. \% }\end{array}$} & \multirow[t]{2}{*}{ AVE\% DIST } \\
\hline Sex: & & & & & & & & & & & \\
\hline Female & 27 & 45.00 & 36 & 11.37 & 32 & 56.14 & 52 & 49.52 & 46 & 61.33 & 51 \\
\hline Male & 33 & 55.00 & 51 & 58.62 & 25 & 43.85 & 53 & 50.47 & 29 & 38.66 & 49 \\
\hline Total & \multicolumn{2}{|c|}{60} & \multicolumn{2}{|c|}{87} & \multicolumn{2}{|c|}{57} & \multicolumn{2}{|c|}{105} & \multicolumn{2}{|c|}{75} & 100 \\
\hline \multicolumn{12}{|l|}{ Marital Status: } \\
\hline Single & 19 & 31.66 & 28 & 32.18 & 15 & 26.31 & 23 & 21.90 & 32 & 42.66 & 31 \\
\hline Married & 31 & 51.66 & 51 & 58.62 & 33 & 57.89 & 65 & 61.90 & 39 & 52.00 & 56 \\
\hline Others & 10 & 16.66 & 8 & 9.19 & 9 & 15.78 & 17 & 16.19 & 4 & 5.33 & 13 \\
\hline Total & \multicolumn{2}{|c|}{60} & \multicolumn{2}{|c|}{87} & \multicolumn{2}{|c|}{57} & \multicolumn{2}{|c|}{105} & \multicolumn{2}{|r|}{75} & 100 \\
\hline \multicolumn{12}{|l|}{ Age: } \\
\hline $20-30$ & 6 & 10.00 & 13 & 14.94 & 9 & 15.78 & 7 & 6.66 & 8 & 10.66 & 12 \\
\hline $31-40$ & 13 & 21.66 & 23 & 26.43 & 15 & 26.31 & 22 & 20.95 & 18 & 24.00 & 24 \\
\hline $41-50$ & 22 & 36.66 & 32 & 36.78 & 21 & 36.84 & 63 & 60.00 & 34 & 45.33 & 43 \\
\hline $51-60$ & 13 & 21.66 & 15 & 17.24 & 7 & 12.28 & 11 & 10.47 & 10 & 13.33 & 15 \\
\hline$>60$ & 6 & 10.00 & 4 & 4.59 & 5 & 8.77 & 2 & 1.90 & 5 & 6.6 & 6 \\
\hline Total & \multicolumn{2}{|c|}{60} & \multicolumn{2}{|c|}{87} & \multicolumn{2}{|c|}{57} & \multicolumn{2}{|c|}{105} & \multicolumn{2}{|r|}{7} & 100 \\
\hline \multicolumn{12}{|l|}{ Education: } \\
\hline Higher Degree & \multicolumn{2}{|r|}{-} & & - & & - & & - & & - & - \\
\hline Degree & 11 & 18.33 & 12 & 13.79 & 10 & 17.54 & 7 & 6.66 & 12 & 16.00 & 14 \\
\hline Secondary & 41 & 68.33 & 65 & 74.71 & 40 & 70.17 & 81 & 77.14 & 59 & 78.66 & 74 \\
\hline Primary & 8 & 13.33 & 10 & 11.49 & 7 & 12.28 & 17 & 16.19 & 4 & 5.33 & 12 \\
\hline Informal & & - & & - & & - & & - & & - & - \\
\hline Total & & 60 & & 87 & & 57 & & 05 & & 75 & 100 \\
\hline Occupation: & & & & & & & & & & & \\
\hline Civil Servants & 4 & 6.66 & 9 & 10.34 & 11 & 19.29 & 7 & 6.66 & 15 & 20.00 & 13 \\
\hline Trading & 6 & 10.00 & 10 & 11.49 & 7 & 12.28 & 14 & 13.33 & 17 & 22.66 & 14 \\
\hline Farming & 49 & 81.66 & 66 & 75.86 & 37 & 64.91 & 83 & 79.04 & 42 & 56.00 & 71 \\
\hline Craft & 1 & 1.66 & 2 & 2.29 & 2 & 3.50 & 1 & 0.95 & 1 & 1.33 & 2 \\
\hline Total & & 60 & & 87 & & 57 & & 05 & & 75 & 100 \\
\hline Income: & & & & & & & & & & & \\
\hline$>30,000$ & 2 & 3.33 & 2 & 2.29 & 1 & 1.75 & 3 & 2.85 & 2 & 2.66 & 3 \\
\hline $25,000-30,000$ & 2 & 3.33 & 6 & 6.89 & 5 & 8.77 & 10 & 9.52 & 6 & 8.00 & 7 \\
\hline $20,000-25,000$ & 15 & 25.00 & 18 & 20.68 & 13 & 22.80 & 17 & 16.19 & 21 & 28.00 & 23 \\
\hline $15,000-20,000$ & 39 & 65.00 & 56 & 64.36 & 34 & 59.64 & 63 & 60.00 & 36 & 48.00 & 59 \\
\hline $10,000-15,000$ & 2 & 3.33 & 5 & 5.74 & 4 & 7.01 & 12 & 11.42 & 10 & 13.33 & 8 \\
\hline Total & & 60 & & 87 & & 57 & & .05 & & 75 & 100 \\
\hline
\end{tabular}




\section{Continued}

Length of Stay:

\begin{tabular}{|c|c|c|c|c|c|c|c|c|c|c|}
\hline $1-5$ & 1 & 1.66 & 1 & 1.14 & 2 & 3.50 & & - & & 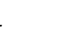 \\
\hline $6-10$ & 3 & 5.00 & 1 & 1.14 & 1 & 1.75 & & - & 2 & 2.66 \\
\hline $11-15$ & 2 & 3.33 & 3 & 3.44 & 2 & 3.50 & 3 & 2.85 & 1 & 1.33 \\
\hline $16-20$ & 5 & 8.33 & 7 & 8.0 & 44 & 7.01 & 2 & 1.90 & 3 & 4.00 \\
\hline Above 20 & 49 & 81.66 & 75 & 86.20 & 48 & 84.21 & 100 & 95.23 & 69 & 92.00 \\
\hline Total & & 0 & & 37 & & 7 & & 05 & & 75 \\
\hline
\end{tabular}

Household Size:

\begin{tabular}{|c|c|c|c|c|c|c|c|c|c|c|}
\hline $1-2$ & 1 & 1.66 & & - & 4 & 7.01 & 2 & 1.90 & 3 & 4.00 \\
\hline $4-5$ & 21 & 35.00 & 28 & 32.18 & 15 & 26.31 & 39 & 37.14 & 26 & 34.66 \\
\hline $6-8$ & 34 & 56.66 & 52 & 59.77 & 36 & 63.15 & 59 & 56.19 & 43 & 57.33 \\
\hline $8-10$ & 4 & 6.66 & 7 & 8.04 & 2 & 3.50 & 5 & 4.76 & 3 & 4.00 \\
\hline Above 10 & & - & & - & & - & & - & & - \\
\hline Total & & 60 & & 87 & & 57 & & 105 & & 75 \\
\hline
\end{tabular}

Source: Researcher's survey data, 2020. Footnotes: Freq-Frequency; \%—Percentage; Ave-Average; Dist—Distribution.

of the respondents have family size of between 7 - 8 members. In rural communities, households usually consist of extended family system. This influences the number of persons in a household. This may affect the quantity of water that is available for an individual thereby, causing poor hygiene condition. The length of stay of the respondents in the study area showed that $1 \%$ lives there between 1 - 5 years, $2 \%$ for $6-10$ years, $3 \%$ for $11-15$ years, $6 \%$ for 16 - 20 years and $88 \%$ for above 20 years. This $88 \%$ may have lived there all their lives an implication that they have general awareness of water related issues in their communities. The remaining $12 \%$ may be immigrants from other communities who settled there in pursuit for work.

\subsection{Water Usage and Sources in the Sampled Communities}

Table 2 shows water usage and sources in the sampled communities. From the respondents' analysis, water sources frequently used in the study area showed that $37 \%$ use river, $18 \%$ use dug well, $18 \%$ use borehole, $7 \%$ use tap water and $20 \%$ buy from tanker trucks. Higher percentage source from the river because it is the only cheaply available option. The $7 \%$ that constantly have access to tap water supply are benefitting from the World Bank assisted water project in that particular community.

The 20\% that buy from tanker truck are the few that can afford it and those that it is their only available option. It showed that $36 \%$ used a particular source due to its quality, $31 \%$ was because of convenient and $33 \%$ was because of constant availability. The $36 \%$ that chose better quality majorly get their water supply from tanker truck, tap and borehole (in high elevation area like Udi). This implies that they are concerned about the reliability of the quality not 
Table 2. Water use and sources in the sample communities.

\begin{tabular}{|c|c|c|c|c|c|c|c|c|c|c|c|}
\hline & & $\begin{array}{l}\text { A } \\
q . \%\end{array}$ & & $\begin{array}{l}\text { B } \\
\text { q. } \%\end{array}$ & & $\begin{array}{l}\text { C } \\
\text { q. } \%\end{array}$ & & $\begin{array}{l}\text { D } \\
\text { q. } \%\end{array}$ & \multicolumn{2}{|c|}{$\begin{array}{c}\text { E } \\
\text { Freq. \% }\end{array}$} & $\begin{array}{c}\text { AVE } \\
\text { DIS? }\end{array}$ \\
\hline \multicolumn{12}{|c|}{ Water source frequently used: } \\
\hline River & 29 & 48.33 & 43 & 49.42 & 32 & 56.14 & 35 & 33.33 & & - & 37 \\
\hline Dugwell & 19 & 31.66 & 28 & 32.18 & 5 & 8.77 & 16 & 15.23 & & - & 18 \\
\hline Borehole & & - & & - & 11 & 19.29 & 8 & 7.61 & 49 & 65.33 & 18 \\
\hline Tap & & - & & - & & - & 35 & 33.33 & & - & 7 \\
\hline Tanker & 12 & 20.00 & 16 & 18.39 & 9 & 15.78 & 11 & 10.49 & 26 & 34.66 & 20 \\
\hline Total & & 60 & & 87 & & 57 & & 05 & & 75 & 100 \\
\hline
\end{tabular}

Reason for the source used:

Affordability
Better quality
Convenient to get
Always available
Others specify
Total

Water source preferred:

Rainwater
River
Dug well
Borehole

$$
\begin{gathered}
\text { Tap } \\
\text { Total }
\end{gathered}
$$

Reason for preferred source:

$$
\begin{gathered}
\text { Affordability } \\
\text { Better quality } \\
\text { Convenient to get } \\
\text { Always available } \\
\text { Others specify } \\
\text { Total }
\end{gathered}
$$

\begin{tabular}{|c|c|c|c|c|c|c|c|c|c|}
\hline 20.00 & 16 & 18.39 & 34 & 59.64 & 46 & 43.80 & 29 & 38.66 & 36 \\
\hline 23.33 & 27 & 31.03 & 16 & 28.07 & 14 & 13.33 & 44 & 58.66 & 31 \\
\hline 56.66 & 44 & 50.57 & 7 & 12.28 & 45 & 42.85 & 2 & 2.66 & 33 \\
\hline - & & - & & - & & - & & - & - \\
\hline 60 & & 87 & & 57 & & 105 & & 75 & 100 \\
\hline
\end{tabular}

Reason for not using the preferred one:

$$
\text { Costly }
$$

\begin{tabular}{|c|c|c|c|c|c|c|c|c|c|}
\hline 86.66 & 72 & 82.75 & 26 & 45.61 & 49 & 46.66 & 8 & 10.66 & 36 \\
\hline 13.33 & 15 & 17.24 & 31 & 58.38 & 21 & 20.00 & 24 & 32.00 & 31 \\
\hline - & & - & & - & 35 & 33.33 & 42 & 56.00 & 33 \\
\hline- & & - & & - & & - & & - & - \\
\hline 60 & & 87 & & 57 & & 105 & & 75 & 100 \\
\hline
\end{tabular}$$
\text { Difficult to get }
$$

Not always available

$$
\text { Not available }
$$$$
\text { Total }
$$

House member involved in fetching water:

$\begin{array}{ccccccccccc}60 & 100 & 87 & 100 & 57 & 100 & 105 & 100 & 75 & 100 & 100 \\ 60 & & 87 & & 57 & 105 & 75 & 100\end{array}$




\section{Continued}

\begin{tabular}{|c|c|c|c|c|c|c|c|c|c|c|c|}
\hline Only Women & \multicolumn{2}{|r|}{ - } & \multicolumn{2}{|r|}{ - } & \multicolumn{2}{|r|}{ - } & \multicolumn{2}{|c|}{ - } & \multicolumn{2}{|r|}{ - } & - \\
\hline Men & 5 & 8.33 & 8 & 9.19 & 3 & 5.26 & 13 & 12.38 & 6 & 8.00 & 19 \\
\hline Only Children & \multicolumn{2}{|r|}{-} & \multicolumn{2}{|r|}{-} & \multicolumn{2}{|r|}{ - } & \multicolumn{2}{|r|}{ - } & \multicolumn{2}{|r|}{ - } & - \\
\hline Women and Children & 55 & 91.66 & 79 & 90.80 & 54 & 94.73 & 92 & 87.61 & 69 & 92.00 & 91 \\
\hline Others specify & \multicolumn{2}{|r|}{-} & \multicolumn{2}{|r|}{-} & \multicolumn{2}{|r|}{-} & \multicolumn{2}{|r|}{-} & \multicolumn{2}{|r|}{ - } & - \\
\hline Total & \multicolumn{2}{|c|}{60} & \multicolumn{2}{|r|}{87} & \multicolumn{2}{|r|}{57} & \multicolumn{2}{|c|}{105} & \multicolumn{2}{|c|}{75} & 100 \\
\hline \multicolumn{12}{|l|}{ Method of storing water: } \\
\hline Tank & 7 & 11.66 & 15 & 17.24 & 7 & 12.28 & 13 & 12.38 & 31 & 41.33 & 19 \\
\hline Drum & 40 & 66.66 & 57 & 65.51 & 42 & 73.68 & 41 & 39.04 & 35 & 46.66 & 58 \\
\hline Keg & 13 & 12.66 & 15 & 17.24 & 8 & 14.03 & 16 & 15.23 & 9 & 12.00 & 16 \\
\hline Bucket & & - & & - & & - & 35 & 33.33 & & - & 7 \\
\hline No response & & - & & - & & - & & - & & - & - \\
\hline Total & & 60 & & 87 & & 57 & & 05 & & 75 & 100 \\
\hline
\end{tabular}

Who should provide water in the Community?

\begin{tabular}{|c|c|c|c|c|c|c|c|c|c|c|c|}
\hline Government & 48 & 80.00 & 67 & 77.01 & 44 & 77.17 & 94 & 89.52 & 68 & 90.66 & 83 \\
\hline Community & 7 & 11.66 & 12 & 13.79 & 4 & 7.01 & 5 & 4.76 & 2 & 2.66 & 8 \\
\hline Public & 5 & 8.33 & 8 & 9.19 & 9 & 15.78 & 6 & 5.71 & 5 & 6.66 & 9 \\
\hline Household & & - & & - & & - & & - & & - & - \\
\hline Others specify & & - & & - & & - & & - & & - & - \\
\hline Total & & 60 & & 87 & & 57 & & 105 & & 75 & 100 \\
\hline
\end{tabular}

Source: Researcher's survey data, 2020. Footnotes: Freq-Frequency; \%-Percentage; Ave-Average; Dist-Distribution.

availability. The result showed that $31 \%$ of the respondents considered convenient while $33 \%$ considered availability. These could be attributed to affordability considering that the sampled communities are low income earners.

All the respondents preferred tap water. The result showed that $55 \%$ preferred it due to good quality, $27 \%$ due to convenience and $18 \%$ due to constant availability. The result also showed that $93 \%$ are not using the preferred source because it is never available. The $7 \%$ that did not respond have access to constant tap water supply.

The survey data of the respondents showed that $91 \%$ of the house members who take the burden of fetching water for household use are the women and children. Only $9 \%$ of men help out in fetching water for household use. This could be that they are pre-occupied with other activities that will yield money for the upkeep of their families.

The percentage distribution of water storage method showed that $19 \%$ store in tanks, $58 \%$ store in drums, $16 \%$ store in kegs and the $7 \%$ had no response. This shows that the majority do not have large water storage capacity container. It is an implication that they will always economize the available quantity. Then the $7 \%$ without response have constant water supply in their premises so have no 
need for storage.

From result analysis, $83 \%$ of the respondents showed that water provision is government responsibility, $8 \%$ showed it is communities responsibility while $9 \%$ showed it is the responsibility of the public. This reveals that the people are aware that it is the responsibility of government to provide water for them with the respondents ranking $83 \%$. From observation, these people feel marginalized knowing that it is their right to have access to sufficient, safe, acceptable, physically accessible and affordable water for domestic uses (Shaheed et al., 2014).

\subsection{COVID-19 Awareness and Preparedness}

Table 3 shows COVID-19 awareness and preparedness. From the respondents' analysis, $18 \%$ got the news of the novel coronavirus through the media, $36 \%$ got the news in church and $46 \%$ heard from their family members. This means that there is general awareness of the novel coronavirus disease in the communities.

The result showed that $94 \%$ have no hand washing facility only $6 \%$ provided it in their homes. This is an indication that majority of the rural communities are not practicing the hand washing preventive measures as directed by the government and health experts as a means to contain COVID-19. The reasons for lack of basic hand washing facility according to the respondents showed that $67 \%$ do not have enough water for use, $16 \%$ showed lack of water affordability; this may be the reason for non constant washing of hands, $7 \%$ showed the facility is costly and $10 \%$ showed lack of community involvement in providing hand washing facilities in common places like markets. This is implication of poor living standard which also has influence in their level of hygiene. From the analysis of how frequent people wash their hands, $62 \%$ frequently wash their hands before and after eating, $15 \%$ wash after using the toilet, $13 \%$ after doing a dirty work and $10 \%$ wash their hands regularly. However, there was no response to hand-washing after touching any surface. From the result, $9 \%$ of the respondents showed that the challenges that hinder following government directives of regular hand washing was no hand washing facility, $51 \%$ showed lack of water availability, $9 \%$ showed no access to clean water, $24 \%$ showed distance of water source. The field observation showed that some communities travel long distance to get clean water for drinking purposes only which they cannot spare for washing of hands. The result showed that $8 \%$ use hand sanitizer in the absence of water, $21 \%$ use alcoholic drinks and $71 \%$ do not use any form of sanitizing agent. This shows that more than half of the respondents are left with the option of using water and soap to maintain hand hygiene but do not have adequate water for the practice. The result of the respondents showed that $51 \%$ use between 10 - 20 litres of water for hygiene purposes per day, 22\% use 21 - 30 litres, $14 \%$ use 31 - 40 litres, $6 \%$ use $41-50$ litres and $7 \%$ use above 50 litres. The people that have access to constant water supply are only $7 \%$. The litres of water available for use per person is an implication that maintaining proper hygiene will be difficult as shown in the survey data that $51 \%$ of the respondents use $10-20$ litres of water per person per day which may exposed them to a high level of infectious diseases 
Table 3. Covid-19 awareness and preparedness.

\begin{tabular}{cccccc} 
A & B & C & D & E & AVE\%DIST \\
Freq. \% & Freq. \% & Freq. \% & Freq. \% & Freq. \% & \\
\hline
\end{tabular}

How did you get news of the novel virus:

\begin{tabular}{|c|c|c|c|c|c|c|c|c|c|c|}
\hline Media & 11 & 18.33 & 17 & 19.54 & 9 & 15.78 & 18 & 17.14 & 14 & 18.66 \\
\hline Village & & - & & - & & - & & - & & - \\
\hline Church & 22 & 36.66 & 22 & 36.78 & 22 & 38.59 & 36 & 34.28 & 26 & 34.66 \\
\hline Family member & 27 & 45.00 & 38 & 43.67 & 26 & 45.61 & 51 & 48.57 & 35 & 46.66 \\
\hline Others specify & & - & & - & & - & & - & & - \\
\hline Total & & 60 & & 87 & & 57 & & 105 & & 75 \\
\hline
\end{tabular}

Hand washing facilities are available in:

Market
Church
Home
Village

None of the above

Total

Reason for lack of basic hand washing facilities:

$$
\begin{gathered}
\text { Lack of water } \\
\text { Affordability of water } \\
\text { Costly to install }
\end{gathered}
$$

Lack of comm. involvement

$$
\text { Total }
$$

How frequently do you wash your hand in a day?

$$
\begin{gathered}
\text { Before/after eating } \\
\text { After using the toilet } \\
\text { Anytime I touch surface } \\
\text { After doing some chores } \\
\text { Regularly } \\
\text { Total }
\end{gathered}
$$

\begin{tabular}{|c|c|c|c|c|c|c|c|c|c|c|}
\hline 66.66 & 52 & 59.77 & 31 & 54.38 & 71 & 67.61 & 48 & 65.33 & & 62 \\
\hline 13.33 & 10 & 11.49 & 12 & 12.05 & 15 & 14.28 & 11 & 14.66 & & 15 \\
\hline- & & - & & - & & - & & - & & - \\
\hline 8.33 & 19 & 21.83 & 7 & 12.28 & 14 & 13.33 & 7 & 9.33 & & 13 \\
\hline 11.66 & 6 & 6.89 & 7 & 12.28 & 5 & 4.76 & 9 & 12.00 & 10 & 10 \\
\hline 6 & & & & 57 & & 05 & & 75 & & 100 \\
\hline
\end{tabular}

What challenges do you face in following government directive of regular hand washing

No hand washing facility

Availability of water

No access to clean water

Distance to water source

$$
\text { No response }
$$$$
\text { Total }
$$

$\begin{array}{lcccccccccc}7 & 11.66 & 11 & 12.64 & 5 & 8.77 & 8 & 7.61 & 4 & 5.33 & 9 \\ 26 & 43.33 & 35 & 40.22 & 33 & 57.89 & 35 & 33.33 & 62 & 82.66 & 51 \\ 9 & 15.00 & 13 & 14.49 & & - & 14 & 13.33 & & - & 9 \\ 18 & 30.00 & 28 & 32.18 & 19 & 33.33 & 13 & 12.38 & 9 & 12.00 & 24 \\ & - & & & & - & 35 & 33.33 & - & 7 \\ 6 & & & & & & & & & & \end{array}$




\section{Continued}

What do you use in absence of water?

\begin{tabular}{|c|c|c|c|c|c|c|c|c|c|c|c|}
\hline Hand sanitizer & 3 & 5.00 & 2 & 2.29 & 5 & 8.77 & 9 & 8.77 & 11 & 14.66 & 8 \\
\hline Alcohol & 11 & 18.33 & 15 & 17.24 & 16 & 28.07 & 22 & 20.95 & 14 & 18.66 & 21 \\
\hline Leaves & & - & & - & & - & & - & & - & - \\
\hline None of the above & 46 & 76.66 & 70 & 80.45 & 36 & 63.15 & 94 & 70.47 & 50 & 66.66 & 71 \\
\hline Others specify & & - & & - & & - & & - & & - & - \\
\hline Total & & 60 & & 87 & & 57 & & 105 & & 75 & 100 \\
\hline
\end{tabular}

How many litres of water do you use per day?

$10-20$
$21-30$
$31-40$
$21-30$
$>50$
Total

$$
\text { Total }
$$

60

$\begin{array}{ll}- & - \\ 87 & 57\end{array}$

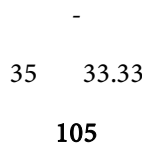

Benefit of accessibility and availability of water:

Improving hygiene culture
Provision of food
Preparation of food
Making money/livelihood
Others specify
Total

\begin{tabular}{cccc}
37 & 61.66 & 54 & 62.06 \\
11 & 18.33 & 14 & 16.09 \\
8 & 13.33 & 12 & 13.79 \\
4 & 6.66 & 7 & 8.04 \\
\multicolumn{2}{c}{-} & & \multicolumn{2}{c}{-}
\end{tabular}

$33 \quad 57.89$

Source: Researcher's survey data, 2020. Footnotes: Freq-Frequency; \%-Percentage; Ave-Average; Dist-Distribution.

(Omarova et al., 2018). Only 7\% have access to above 50 liters of water which is the volume a person needs per day to meet personal hygienic needs (Rumalongo et al., 2017). According to the result analysis, $65 \%$ showed that access to water and availability will improve hygienic culture of the people, $18 \%$ showed it will help in food provision, 9\% showed it will help in food preparation and $2 \%$ showed it will improve livelihood. A higher percentage agrees that adequate water supply can improve hygiene condition of the people. This shows that lack of availability and accessibility affect the volume of water people use (Bain et al., 2014) and hinders proper hygiene practice.

\section{Conclusion}

This study examined the challenges of rural communities in Enugu West Senatorial district to the COVID-19 in terms of access to clean water supply for proper hygiene. Although the survey showed general awareness of the pandemic in all the communities, the preparedness level for regular hand washing was still very low. This is attributed to lack of adequate water supply in the communities. A large number of the respondents admit that adequate access to clean water 
supply would enhance the people's hygiene lifestyle.

The result showed that the rural communities would be vulnerable to contracting and spreading COVID-19 disease due to lack of access to adequate water supply for regular washing of hands. It recommends government swift intervention by extending water borehole projects and water treatment plants to various rural communities as well as providing maintenance services for non-functional ones.

\section{Acknowledgements}

My profound gratitude goes to three anonymous referees for their constructive comments on my manuscript. Special thanks to a senior colleague for his useful comments and research ideas. I take responsibility for all errors and omission.

\section{Conflicts of Interest}

The authors declare no conflicts of interest regarding the publication of this paper.

\section{References}

Abubakar, I. R. (2016). Quality Dimension of Public Services in Abuja, Nigeria. Utility Policy, 38, 43-51. https://doi.org/10.1016/j.jup.2015.12.003

Adhikari, S. P., Meng, S., Wu, Y., Mao, Y., Ye, R., Wang, Q., Sun, C., Sylvia, S., Rozelle, S., Raat, H., \& Zhou, H. (2020). Epidemiology, Causes, Clinical Manifestation and Diagnosis, Prevention and Control of Coronavirus Disease (COVID-19) during the Early Outbreak Period: A Scoping Review. Infectious Diseases of Poverty, 9, 29. https://doi.org/10.1186/s40249-020-00646-x

Akpabio, E. M. (2012). Water Supply and Sanitation Services Sector in Nigeria: The Policy Trend and Practice Constraints. ZEF Working Paper Series, No. 96, Bonn: University of Bonn, Center for Development Research (ZEF).

Bain, R. E. S., Wright, J. A., Christenson, E., \& Bartram, J. K. (2014). Rural: Urban Inequalities in Post 2015 Targets and Indicators for Drinking-Water. Science of the Total Environment, 490, 509-513. https://doi.org/10.1016/j.scitotenv.2014.05.007

Behera, B., Rahut, D., \& Sethi, N. (2020). Analysis of Household Access to Drinking Water, Sanitation, and Waste Disposal Services in Urban Areas of Nepal. Utility Policy, 62, Article ID: 100996. https://doi.org/10.1016/j.jup.2019.100996

Bourouiba, L. (2020). Turbulent Gas Clouds and Respiratory Pathogen Emissions. Journal of the American Medical Association. https://doi.org/10.1001/jama.2020.4756

Elimelech, M. (2006). The Global Challenge for Adequate and Safe Water. Journal of Water Supply: Research and Technology, 55, 3-10. https://doi.org/10.2166/aqua.2005.064

Ezbakhe, F., Giné-Garriga, R., \& Pérez-Foguet, A. (2019). Leaving No One behind: Evaluating Access to Water, Sanitation and Hygiene for Vulnerable and Marginalized Groups. Science of the Total Environment, 683, 537-546. https://doi.org/10.1016/j.scitotenv.2019.05.207

Guégan, J. F., Suzan, G., Kati-Coulibaly, S., Bonpamgne, D. N., \& Moatti, J. P. (2018). Sustainable Development Goal 3, "Health and Well-Being", and the Need for More Integrated Thinking. Veterinaria México $O A, 5,1-18$. 
https://www.worldometers.info/coronavirus

Hutton, G. (2016). Editorial: Can We Meet the Costs of Achieving Safely Managed Drinking Water, Sanitation and Hygiene Services under the New Sustainable Development Goals? Journal of Water, Sanitation and Hygiene for Development, 6, 191-194. https://doi.org/10.2166/washdev.2016.037

Kampf, G., Todt, D., Pfaender, S., \& Steinmann, E. (2020). Persistence of Coronaviruses on Inanimate Surfaces and Their Inactivation with Biocidal Agents. Journal of Hospital Infection, 104, 246-251. https://doi.org/10.1016/j.jhin.2020.01.022

Kumwenda, S. (2019). Challenges to Hygiene Improvement in Developing Countries: The Relevance of Hygiene to Health in Developing Countries. London: IntechOpen Publisher. https://doi.org/10.5772/intechopen.80355

National Population Commission, NPC (2006). Report of Nigeria's National Population Commission on the 2006 Census. Population and Development Review, 33, 206-210. http://www.jstor.org/stable/25434601

Nigeria Centre for Disease Control (NCDC) (2020). Coronovirus (COVID-19) Highlights: Case Summary in Nigeria 7th April, 2020. https://covid19.ncdc.gov.ng

Nzeadibe, T. C., \& Ajaero, C. K. (2010). Assessment of Socio-Economic Characteristics and Quality of Life Expectations of Rural Communities in Enugu State Nigeria. Applied Research Quality Life, 2, 353-371. https://doi.org/10.1007/s11482-010-9096-4

Omarova, A., Tussupova, K., Berndtsson, R., Kalishev, M., \& Sharapatova, K. (2018). Protozoan Parasites in Drinking Water: A System Approach for Improved Water, Sanitation and Hygiene in Developing Countries. International Journal of Environmental Research and Public Health, 15, 495. https://doi.org/10.3390/ijerph15030495

Rumalongo, L., Nathengwe, N. S., \& Musyoki, A. (2017). The Nature of Urban Household Water Demand and Consumption in Makhado Local Municipality: A Case Study of Makhado Newtown. Procedia Environmental Sciences, 37, 182-194. https://doi.org/10.1016/j.proenv.2017.03.033

Shaheed, A., Orgill, J., Montgomery, M. A., Jeuland, M. A., \& Brownd, J. (2014). Why "Improved" Water Sources Are Not Always Safe. Bulletin of the World Health Organization, 92, 283-289. https://doi.org/10.2471/BLT.13.119594

Short, K. R., Kedzierska, K., \& Van de Sandt, C. E. (2018). Back to the Future: Lessons Learned From the 1918 Influenza Pandemic. Frontiers in Cellular and Infection Microbiology, 8, 343. https://doi.org/10.3389/fcimb.2018.00343

Tadesse, A., Bosona, T., \& Gebresenbet, G. (2013). Rural Water Supply Management: The Case of Adama Area, Ethiopia. Journal of Water Resources and Protection, 5, 208-221. https://doi.org/10.4236/jwarp.2013.52022

World Health Organization WHO, \& United Nations International Children's Emergency Fund (2017). JMP Methodology: Update and SDG Baselines.

https://washdata.org/sites/default/files/documents/reports/2018-04/JMP-2017-updatemethodology.pdf

World Health Organization WHO (2017). Progress on Drinking Water, Sanitation and Hygiene: Update and SDG Baseline.

https://apps.who.int/iris/bitstream/handle/10665/258617/9789241512893eng.pdf;jsessi onid=757602F8D9B75D5B8CADFFBF91CED5C2? sequence $=1$

World Health Organization WHO (2020). Statement on the Second Meeting of the International Health Regulations Emergency Committee Regarding the Outbreak of Novel Coronavirus (2019-CoV).

Worldometer (2020). COVID-19 Coronavirus Pandemic. 
WWAP (UNESCO World Water Assessment Programme) (2019). The United Nations World Water Development Report 2019: Leaving No One Behind. Paris, UNESCO. https://reliefweb.int/sites/reliefweb.int/files/resources/367306eng.pdf 